\title{
What are the possibilities of spontaneous resorption of a thoracic disc herniation occupying more than $20 \%$ of the spinal canal in the asymptomatic subject? Comparative study
}

\author{
David Brauge ${ }^{\mathrm{a}, \mathrm{b}, *}$, Rachid Madkouri $^{\mathrm{a}}$, Robert Clément ${ }^{\mathrm{a}}$, Vincent Reina ${ }^{\mathrm{a}}$, Thomas Brauge ${ }^{\mathrm{c}}$, \\ Stephan Gaillard ${ }^{a}$ \\ a Service de Neurochirurgie, Hôpital Foch, Suresnes, France \\ ${ }^{\mathrm{b}}$ Institut de Biomécanique Humaine Georges Charpak Arts et Métiers Paris Tech, Paris, France \\ ${ }^{\mathrm{c}}$ Université de Lille 1, Science et Technologie, Villeneuve d'Ascq, France
}

Keywords:

Thoracic disc herniation

Spontaneous regression

Thoracic spine

Calcific herniation

Spinal cord compression

Thoracic myelopathy

Resorption

\begin{abstract}
A B S T R A C T
Thoracic disc herniation is a rare pathology for which surgical treatment is difficult. The discovery of asymptomatic or only slightly symptomatic lesions can be problematic, especially in cases of marked canal stenosis. The possibility of spontaneous resorption has been documented by a few case reports but there is no study on this subject. Our objective was to compare the clinical and radiological data for two groups of patients with significant thoracic herniation (occupying more than $20 \%$ of the spinal canal): one showing spontaneous resorption (group 1) and the other persistence of the lesion during follow up (group 2). The physiological processes of thoracic herniation are also discussed. We present a retrospective study of our database of patients with thoracic hernia. Only subjects who initially showed signs of slight or absent myelopathy (Frankel D or E) were included. Group 1 and 2 are composed of 12 and 17 patients respectively. The clinical and radiological data are compared. The two groups were not different for the following parameters: age, sex ratio, disc calcification, size, trajectory, side, hernia level. Other parameters were evaluated and were not associated with a higher rate of resorption: disc calcification, intramedullary hypersignal in T2 sequence, calcification of the posterior common vertebral ligament, calcification of another disc and Scheuerman's disease. Asymptomatic thoracic disc herniation is a condition that can disappear spontaneously, even in the case of a large lesion. To date, there are no clinical or radiological data that can predict such an evolution.
\end{abstract}

\section{Introduction}

Thoracic disc herniation (TDH) is a condition rarely observed in medical practice. Although radiological series estimate the frequency of this lesion at between 11 and $14.5 \%$, lesions are mostly minimal and asymptomatic $[1,2]$. The frequency of symptomatic thoracic disc hernias is estimated to be 1 case per million in the general population [3]. The main reasons for consultation are: back pain, intercostal neuralgia (ICN) and myelopathy.

While the need for a surgical procedure is commonly accepted in cases of symptomatic hernia with a sign of myelopathy, the medical management of cases with an asymptomatic or only slightly symptomatic lesion may be debated, especially if the lesion is voluminous, since the risk associated with an intervention is not negligible, ranging from $3.7 \%$ to $66.6 \%$ of complications in the most recent series [4-9]. A study of the literature on significant TDH ( $>20 \%$ of the spinal canal) revealed a small number of case reports noting spontaneous resorption [10-14]. We report here a series of 12 patients followed between January 1, 2009 and January 1, 2016, who were sent to our center for management of significant TDH (occupying more than $20 \%$ of the spinal canal). All of these patients experienced spontaneous resorption of their lesions. The characteristics of this series are compared with those of a cohort of asymptomatic patients with TDH of the same size in whom lesion resorption was not demonstrated during the same follow-up period. The mechanisms that may explain this particular evolution are considered in the discussion. 


\section{Methods}

\subsection{Design}

Between January 2006 and January 2016, 132 subjects were referred to our center for thoracic disc herniation. We present a retrospective study using this prospectively established patient database. The inclusion criteria were: referred for TDH $>20 \%$ of the spinal canal and absence of signs of severe myelopathy in connection with the hernia during follow up (Frankel E or D). Patients who were seen only once in consultation (2nd opinion, misdiagnosis) were excluded, as were patients who had surgery due to disabling symptoms related to TDH.

Based on radiological follow-up data, 2 groups were formed. Group 1: patients with spontaneous regression of the herniation, and Group 2: patients in whom an aspect of compression persisted. The diagnosis of resorption of the hernia was based on MRI showing total or subtotal disappearance ( $<5 \%$ of the spinal canal) of the initial lesion. A detailed example of two patients belonging to group 1 is given in Figs. 1 and 2.

\subsection{Comparison of the two groups}

All the patients were seen in consultation and examined by the same practitioner with expertise in the management of these pathologies. The initial diagnosis of TDH was based on a vertebro-medullary MRI and a computed tomography (CT) scan. When there was no evidence of medullary dysfunction, an electrophysiological examination (Somatosensory and Motor Evoked Potentials) was performed in search of subclinical myelopathy. In case of minimal abnormality, the management consisted of clini-
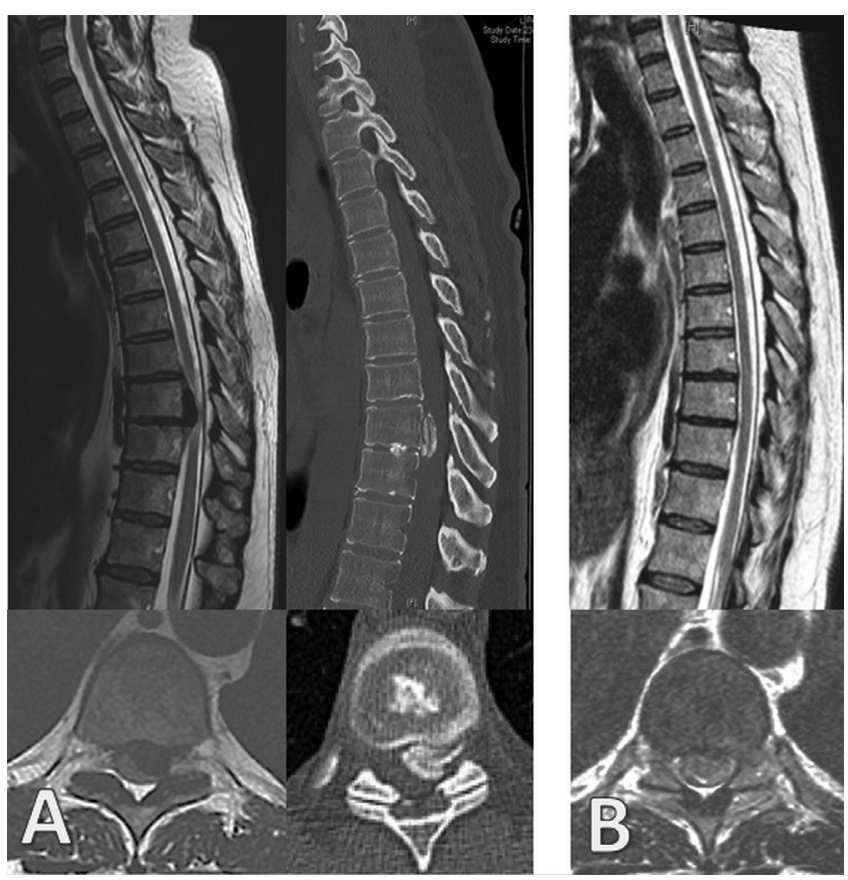

Fig. 1. A 51-year-old patient who complained of left-sided intercostal neuralgia secondary to coughing effort. Two and a half months after the onset, she presented neuropathic pain in the left lower limb. No neurologic deficit was found on the day of the consultation. The somesthetic evoked potentials were discretely slowed down; the evoked motor potentials were normal. The CT scan and T2-weighted MRI found a calcified T9-T10 thoracic disc herniation of ascending path (A). The decision taken was supervision. At 8 months, the pain disappeared and MRI confirmed the resorption of the lesion (B). The electrophysiological assessment was unchanged.
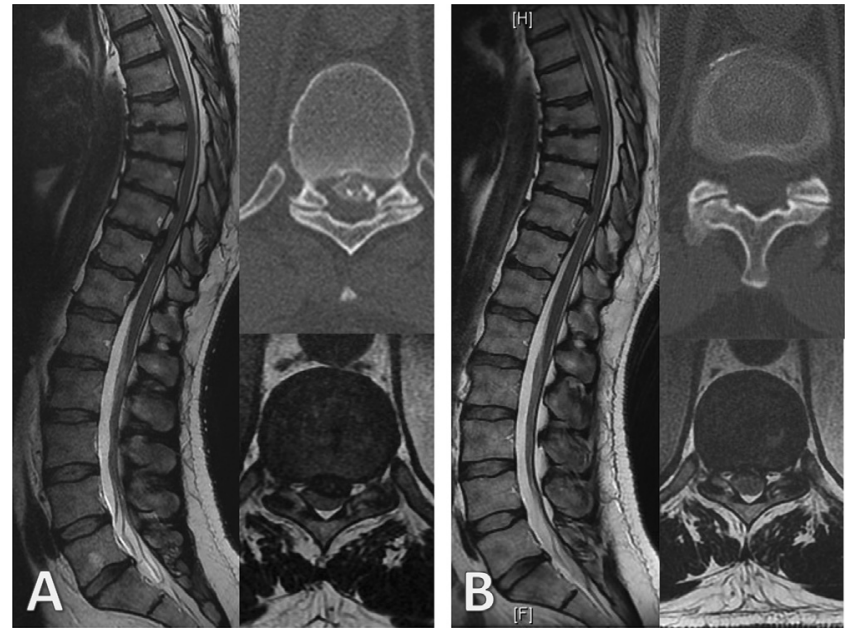

Fig. 2. A 43-year-old patient who described dorsalgia and paresthesia of the lower limbs that appeared after a run. On the day of the consultation, the neurological examination was normal except for the paresthesia, which persisted; there was no associated sensory deficit. The somesthetic evoked potentials showed a discrete slowing of conduction. Initial examinations revealed a large calcified hernia at T10T11 associated with calcification of the posterior longitudinal ligament, there was another hernia at T9T10 (A). At 5 months of evolution, the symptomatology regressed and the evoked potentials normalized. The radiological assessment confirmed a sub-total regression of the T10T11 not that of T9T10 hernia (B).

cal, radiological and electriophysiological monitoring. The two groups were compared on the data resulting from these examinations. Concerning the hernia, the following parameters were observed: level, side, calcified character, degree of stenosis of the spinal canal (expressed in percentage), intramedullary hypersignal in MRI T2 sequence with respect to the hernia. Other morphological data from the analysis of the rest of the thoracic spine were noted: second hernia, calcification of other discs, posterior longitudinal ligament calcification, and Scheuerman's disease. The calcified character of the different structures was evaluated on the initial CT scan. Two independent Spine Surgeon reviewed all of radiological data.

\subsection{Statistical analysis}

All data were presented as mean \pm standard deviation (SD) or median (Interquartile range) depending on the normal or abnormal distribution of the data. For the bivariate analysis, the comparison between the two groups relied on percentage comparison tests (chi-square test) for qualitative variables and on mean comparison tests (Student $t$-test) for quantitative variables. Statistical significance was evaluated at $P<0.05$. Calculations were performed with Statgraphics 233 centurion XVI (Sigma plus, Paris, France).

\section{Results}

\subsection{Clinical results}

Group 1 consisted of 12 patients ( 8 women, 4 men). Their mean age was 49.9 (SD 7.0) years. The characteristics of these patients are shown in Table 1 . The symptoms that led to the discovery of these lesions are reported. On average, the follow up was 57.4 (SD 41.9) weeks. Group 2 consisted of 17 subjects (12 women, 5 men). Their mean age was 49.0 (SD 11.5) years. The two groups were not significantly different for age $(p=0.809)$ or sex ratio $(p=0.900)$. At the end of the study, all patients were clinically stable or improved. 
Table 1

Clinical data for Group 1.

\begin{tabular}{|c|c|c|c|c|c|c|c|}
\hline Patient & Gender & Age & Clinical symptoms at first consultation & Physical examination & $\begin{array}{l}\text { Evoked } \\
\text { Potential }\end{array}$ & $\begin{array}{l}\text { Follow } \\
\text { up }\end{array}$ & $\begin{array}{l}\text { Last Clinical } \\
\text { Statu }\end{array}$ \\
\hline 1 & $\mathrm{~F}$ & 51 & $\begin{array}{l}\text { Rachialgia + InterCostal neuralgia (ICN) + Neuropathic } \\
\text { pain in left lower limb }\end{array}$ & Normal & $\begin{array}{l}\text { Slightly slowed } \\
\text { down }\end{array}$ & 9,4 & Rachialgia \\
\hline 2 & M & 40 & Rachialgia + ICN & Normal & Not done & 3,3 & Asymptomatic \\
\hline 3 & $\mathrm{~F}$ & 41 & Rachialgia + ICN & Normal & Normal & 6,0 & $\begin{array}{l}\text { Rachialgia } \\
+ \text { mild ICN }\end{array}$ \\
\hline 4 & M & 43 & Rachialgia + dorsalgia + paresthesia of lower limb & Normal & Normal & 4,8 & Asymptomatic \\
\hline 5 & $\mathrm{~F}$ & 58 & Rachialgia & $\begin{array}{l}\text { Ataxia and hyperreflexia of } \\
\text { lower limbs }\end{array}$ & $\begin{array}{l}\text { Slightly slowed } \\
\text { down }\end{array}$ & 15,8 & Asymptomatic \\
\hline 6 & $\mathrm{~F}$ & 54 & Rachialgia & Normal & Not done & 16,0 & Asymptomatic \\
\hline 7 & $\mathrm{~F}$ & 50 & Rachialgia + ICN & Normal & Not done & 6,1 & Mild ICN \\
\hline 8 & $\mathrm{~F}$ & 57 & Rachialgia + ICN & Normal & $\begin{array}{l}\text { Slightly slowed } \\
\text { down }\end{array}$ & 14,9 & Asymptomatic \\
\hline 9 & $\mathrm{~F}$ & 62 & Rachialgia & Normal & Not done & 8,3 & Asymptomatic \\
\hline 10 & M & 48 & Rachialgia + ICN & Normal & Not done & 14,1 & Asymptomatic \\
\hline 11 & $\mathrm{~F}$ & 44 & Fortuitous (low back pain exploration) & Hyperreflexia & $\begin{array}{l}\text { Slightly Slowed } \\
\text { down }\end{array}$ & 21,4 & Asymptomatic \\
\hline 12 & M & 51 & $\begin{array}{l}\text { Neuropathic pain in left lower limb then neurogenic } \\
\text { claudication }\end{array}$ & $\begin{array}{l}\text { Old pyramidal syndrome } \\
\text { (post poliomyelitis) }\end{array}$ & $\begin{array}{l}\text { Non } \\
\text { interpretable }\end{array}$ & 38,3 & Unchanged \\
\hline
\end{tabular}

Table 2

Comparison of Radiological results in the two groups.

\begin{tabular}{|c|c|c|c|}
\hline & Group 1 & Group 2 & $\mathrm{p}$ \\
\hline Calcified herniation & $11 / 12$ & $15 / 17$ & 0.900 \\
\hline Canal stenosis (\%) & $42.7($ SD 13.3) & 43.5 (SD 17.2) & 0.897 \\
\hline Level of hernia ((T1-T3, T4-T8, T9-T12) & $0 / 12,6 / 12,6 / 12$ & $1 / 17,10 / 17,6 / 17$ & 0.900 \\
\hline Side of the hernia (left, right, middle) & $4 / 12,3 / 12,5 / 12$ & $6 / 17,1 / 17,10 / 17$ & 0.900 \\
\hline Location of the hernia (median, posterolateral, foraminal) & $9 / 12,3 / 12,0 / 12$ & $14 / 17,3 / 17,0 / 17$ & 0.900 \\
\hline Trajectory of the hernia (horizontal, upward, downward) & $5 / 12,6 / 12,1 / 12$ & $15 / 17,1 / 17,1 / 17$ & 0.990 \\
\hline Calcification of the disc & $11 / 12$ & $11 / 17$ & 0.950 \\
\hline 2nd thoracic herniation & $02 / 12$ & $03 / 17$ & 0.100 \\
\hline Calcification of other disc & $06 / 12$ & $03 / 17$ & 0.950 \\
\hline Calcification of posterior longitudinal Ligament & $2 / 12$ & $1 / 17$ & 0.900 \\
\hline High T2-weighted imaging signal intensity in spinal cord & $3 / 12$ & $3 / 17$ & 0.900 \\
\hline Scheuerman disease (sorensen criteria) & $01 / 12$ & $4 / 17$ & 0.900 \\
\hline
\end{tabular}

\subsection{Radiological results}

The radiological data of the two groups are shown in Table 2. In all cases of calcified hernia there was an associated disc calcification. In group 1 , there was only one patient with a non-calcified hernia (patient 12). There were no significant differences between the two groups over all the parameters studied.

\section{Discussion}

Thoracic disc herniation is a rare condition and can sometimes be difficult to treat. While all authors agree on the need to treat patients with disabling myelopathy, there is no consensus in the case of a large hernia in a patient with minor symptoms. The evolution of our patients belonging to group 1 seems to indicate that a simple clinical and radiological follow-up is sometimes sufficient, with regression of the symptoms and disappearance of almost all the initial lesions in a time varying from 3.3 to 38.3 months. Concerning this time to resorption, it is interesting to note that the patient with the longest follow-up duration was also the only one who had a non-calcified hernia (patient 12). This original study does not allow us to determine clinical or radiological parameters that are associated with spontaneous regression of the hernia. Given the rarity of this condition, a multi-center collection of similar cases would be required to determine such prognostic factors of regression.

\subsection{Mechanism of resorption of disc herniation and specific case of thoracic hernias}

Spontaneous resorption of a herniated disc is a well-known phenomenon at the lumbar and cervical level $[15,16]$. On the physiopathological view, it is an inflammatory reaction mediated by TNF $\alpha$ which will lead to a neoangiogenesis an influx of macrophages at the site of the hernia [17-19]. This is reflected by a contrast enhancement around the hernia, clearly visible in MRI. This phenomenon is visible from 2 months and can continue for 1 year after the initial pain [20].

For TDH, things seem different as it concerns a segment of the spine that is not very mobile and the symptoms of hernia rarely manifest themselves in a brutal way, following a false movement for example. In fact, it seems that there are two different nosological entities: the existence of a soft hernia, of the fibrous type, which will be found more in posterolateral variety because of the existence of the Posterior Longitudinal Ligament, and the calcified herniation, the symptoms of which are mostly progressive. While it is generally accepted that a soft hernia can be reversed, little is known about the mechanisms of resorption of calcified hernias. In this particular case, the analysis of the disc and hernia volumes suggests that the appearance of a calcified herniation is not so much the result of an expulsion of disc material but rather the accumulation of calcium deposit. Those authors suggest a crystalline deposition disease [21]. 


\subsection{Relationship between disc calcification and calcified hernia}

In our study it is interesting to note that $100 \%$ of calcified hernias were associated with disc calcifications. In fact, it seems that the appearance of calcified TDH is linked to disc calcifications. This observation has been made by several authors [4,22]. It would seem that the existence of a disc calcification is the first event, the appearance of a hernia then being due to a backward migration of this calcified material, as Awwad's nuclear trail sign could testify [23].

There are two types of disc calcification: chronic, possibly symptomatic or not, and acute with inflammatory symptoms. These very symptomatic forms are most often encountered in the pediatric population at cervical level but some cases have been reported in adults at the thoraco-lumbar spine. The evolution of the acute forms is documented by numerous case reports, which often indicate a spontaneous resolution with disappearance of the symptomatology in a few weeks [24,25]. Radiologically, there is also a regression, often incomplete, of the calcifications. For the chronic forms, the spontaneous evolution is much less documented. It seems clear that certain metabolic disorders such as hemochromatosis or articular chondrocalcinosis favor disc calcifications [26-28]. This type of lesion may also be observed in older patients with spinal static disorders responsible for accelerated discopathy $[29,30]$.

\subsection{A manifestation of an hydroxyapatite cristal deposition ?}

Anatomopathologic studies on disc calcification seem rather discordant and different results can be found in the literature, reporting crystals of hydroxyapatite (HA) [31], crystals of calcium pyrophosphate (CaPP) [32], crystals of calcium associated with fat [4] Systematic cadaveric analysis suggests that HA deposition is more frequent than CaPP deposits on the spine. However, it seems that, for a genuine HA deposition disease, the two types of crystals (HA and PPCa) can be observed concomitantly. Hydroxyapatite crystals are microcrystals that can be deposited peri- or intra-articularly, sometimes producing particularly impressive macroscopic clusters. The most frequent attacks involve the tendons of the shoulder but all the joints, including the spine, may be affected. Several clinical forms can be found: asymptomatic, painful acute, or chronic. Classically, the symptomatic forms respond to medical treatment with anti-inflammatory drugs or infiltration. Total or partial spontaneous regression of these calcifications has been described, including for voluminous forms $[33,34]$. Finally HA deposition disease mainly affects subjects between 40 and 60 years old as our population study. In our opinion, all these elements suggest that our cases of calcified HDT that showed spontaneous regression were, in fact, HA crystal deposition pathologies. However, these data would have to be confirmed by comprehensive anatomopathological studies.

\section{Conclusion}

We present a comparative study of paucisymptomatic patients with a thoracic disc herniation occupying more than $20 \%$ of the spinal canal. Twelve patients experienced spontaneous resorption of the lesion, proved by MRI follow-up. In almost all cases the hernia was of the calcified type. Comparison of this group of patients with a group in which the lesions persisted did not allow us to detect a factor associated with spontaneous disappearance. Among the patients with thoracic disc herniation who are not symptomatic, some will develop a true myelopathy and others will remain asymptomatic, with spontaneous regression of the lesion in a number of cases. This seems to indicate that, in the absence of signs of severe myelopathy, it is preferable to perform regular clinical, radiological and electrophysiological monitoring rather than to envisage surgical treatment, even in the case of a large lesion.

\section{Conflict of interest and source of funding}

None were declared.

\section{References}

[1] Williams MP, Cherryman GR, Husband JE. Significance of thoracic disc herniation demonstrated by MR imaging. J Comput Assist Tomogr 1989;13 (2):211-4.

[2] Wood KB, Garvey TA, Gundry C, Heithoff KB. Magnetic resonance imaging of the thoracic spine. Evaluation of asymptomatic individuals. J Bone Joint Surg Am 1995;77(11):1631-8.

[3] Carson J, Gumpert J, Jefferson A. Diagnosis and treatment of thoracic intervertebral disc protrusions. J Neurol Neurosurg Psychiatry 1971;34 (1):68-77.

[4] Gille O, Soderlund C, Razafimahandri HIC, Mangione P, Vital J-M. Analysis of hard thoracic herniated discs: review of 18 cases operated by thoracoscopy. Eur Spine J 2006;15(5):537-42.

[5] Ayhan S, Nelson C, Gok B, et al. Transthoracic surgical treatment for centrally located thoracic disc herniations presenting with myelopathy: a 5-year institutional experience. J Spinal Disord Tech 2010;23(2):79-88.

[6] Quint U, Bordon G, Preissl I, Sanner C, Rosenthal D. Thoracoscopic treatment for single level symptomatic thoracic disc herniation: a prospective followed cohort study in a group of 167 consecutive cases. Eur Spine J 2012;21 (4):637-45.

[7] Wait SD, Fox DJJ, Kenny KJ, Dickman CA. Thoracoscopic resection of symptomatic herniated thoracic discs: clinical results in 121 patients. Spine 2012;37(1):35-40.

[8] Nishimura Y, Thani NB, Tochigi S, Ahn H, Ginsberg HJ. Thoracic discectomy by posterior pedicle-sparing, transfacet approach with real-time intraoperative ultrasonography. J Neurosurg Spine 2014;21(4):568-76.

[9] Zhuang QS, Lun DX, Xu ZW, Dai WH, Liu DY. Surgical treatment for central calcified thoracic disk herniation: a novel l-shaped osteotome. Orthopedics 2015;38(9):e794-8.

[10] Ahmad FU, Schallert E, Bregy A, Post JD, Vanni S. Disappearing large calcified thoracic disc herniation in a patient with thalassaemia. BMJ Case Rep 2016;2016.

[11] Eap C, Bennis S, Blauwblomme T, et al. Spontaneous resorption of thoracic calcified disc herniation: report of two cases and review of the literature. Neurochirurgie 2012;58(6):353-7.

[12] Haro H, Domoto T, Maekawa S, et al. Resorption of thoracic disc herniation. J Neurosurg Spine 2008;8(3):300-4.

[13] Piccirilli M, Lapadula G, Caporlingua F, Martini S, Santoro A. Spontaneous regression of a thoracic calcified disc herniation in a young female: a case report and literature review. Clin Neurol Neurosurg 2012;114(6):779-81.

[14] Xu N, Wei F, Liu X, Jiang L, Liu Z. Calcific discitis with giant thoracic disc herniations in adults. Eur Spine J 2016;25(1):204-8.

[15] Maigne J-Y, Rime B, Deligne B. Computed tomographic follow-up study of forty-eight cases of nonoperatively treated lumbar intervertebral disc herniation. Spine 1992;17(9):1071-4.

[16] Mochida K, Komori H, Okawa A, et al. Regression of cervical disc herniation observed on magnetic resonance images. Spine 1998;23(9):990-5.

[17] Haro H, Kato T, Komori H, Osada M, Shinomiya K. Vascular endothelial growth factor (VEGF)-induced angiogenesis in herniated disc resorption. J Orthop Res 2002;20(3):409-15.

[18] Koike Y, Uzuki M, Kokubun S, Sawai T. Angiogenesis and inflammatory cell infiltration in lumbar disc herniation. Spine 2003;28(17):1928-33.

[19] Kato T, Haro H, Komori H, Shinomiya K. Sequential dynamics of inflammatory cytokine, angiogenesis inducing factor and matrix degrading enzymes during spontaneous resorption of the Herniated disc. J Orthop Res 2004;22 (4):895-900.

[20] Autio RA, Karppinen J, Niinimäki J, et al. Determinants of spontaneous resorption of intervertebral disc herniations. Spine 2006;31(11):1247-52.

[21] Coumans J-VCE, Neal JB, Grottkau BE, et al. Giant thoracic osteophyte: a distinct clinical entity. J Clin Neurosci 2016;21(9):1599-602.

[22] Stillerman CB, Chen TC, Couldwell WT, Zhang W, Weiss MH. Experience in the surgical management of 82 symptomatic herniated thoracic discs and review of the literature. J Neurosurg 1998;88(4):623-33.

[23] Awwad EE, Martin DS, Smith KRJ, Baker BK. Asymptomatic versus symptomatic herniated thoracic discs: their frequency and characteristics as detected by computed tomography after myelography. Neurosurgery 1991;28 (2):180-6.

[24] Nogueira-Barbosa MH, da Silva Herrero CFP, Pasqualini W, Defino HLA. Calcific discitis in an adult patient with intravertebral migration and spontaneous remission. Skeletal Radiol 2013;42(8):1161-4.

[25] Shah A, Botchu R, Grainger MF, Davies AM, James SL. Acute symptomatic calcific discitis in adults: a case report and review of literature. Skeletal Radiol 2015;44(12):1819-24 
[26] Weinberger A, Myers AR. Intervertebral disc calcification in adults: a review. Semin Arthritis Rheum 2015;8(1):69-75.

[27] Ballou SP, Asim Khan M, Kushner I. Diffuse intervertebral disk calcification in primary amyloidosis. Ann Intern Med 1976;85(5):616-7.

[28] Aessopos A, Tsironi M, Polonifi K, Baltopoulos P, Vaiopoulos G. Intervertebra disc calcification in thalassemia intermedia. Eur J Haematol 2008;80(2):164-7.

[29] Chanchairujira K, Chung CB, Kim JY, et al. Intervertebral disk calcification of the spine in an elderly population: radiographic prevalence, location, and distribution and correlation with spinal degeneration. Radiology 2004;230 (2):499-503.
[30] Hristova GI, Jarzem P, Ouellet JA, et al. Calcification in human intervertebral disc degeneration and scoliosis. J Orthop Res 2011;29(12):1888-95.

[31] Lipson SJ, O'Connell JX. Case 37-1991: a 47-year-old woman with back pain and a lesion n a vertebral body. N Engl J Med 1991;325(11):794-9.

[32] Srinivasan V, Kesler H, Johnson M, Dorfman H, Walter K. Tophaceous pseudogout of the thoracic spine. Acta Neurochir 2012;154(4):747-50.

[33] Garcia GM, McCord GC, Kumar R. Hydroxyapatite crystal deposition disease. Semin Musculoskelet Radiol 2003:7(3):187-93.

[34] Siegal DS, Wu JS, Newman JS, Del Cura JL, Hochman MG. Calcific tendinitis: a pictorial review. Can Assoc Radiol J 2009;60(5):263-72. 